\section{Save-As Detroit: \\ Connecting Successful Real World and Academic Projects}

Allegra Pitera

University of Detroit Mercy
Over time I have seen various attempts, both successes and failures to 'save' Detroit. Some of the late-20th Century development projects were intended to save the city, such as John Portman's Renaissance Center downtown on the river. However, the development trend in that era was to turn their backs on the urban landscape, razie historic buildings and vibrant neighborhoods: the developers lacked a sensitivity to the existing urban context. They could not see the potential value of robust communities and a walkable urban streetscape; they were trying to save Detroit.

Before defining Save-As, let's define what Save-As is not. The issue with saving Detroit is partly that those doing the saving often presume to know what the city needs, and worse, turn their backs on the communities and the citizens who live and work there.

As we know when working on a computer, there is an option for saving a project you are working on without destroying the previous version. It is called Save-as. Urban visionaries understand that if we re-vision Detroit through a contemporary design lens, if Saved-As, we have the opportunity to merge modern urban design strategies with the strengths of the existing framework, such as Detroit's communities, culture and beautiful architecture. In doing so, ultimately enhancing the quality of life for urban-dwellers as well as the surroundings, benefiting through economic growth and vibrant neighborhoods. In this context, Save-As is therefore about retaining what works-and building up from there. As an educator, I feel that this is an important distinction for students to understand: to not try to save Detroit.

The current Detroit riverfront now boasts a renovated Renaissance Center: thankfully there is no more concrete berm. The riverfront now consists of walkable and vibrant public spaces. One of my hunches in this research is that successful projects like this retain less of an emphasis on saving as they do in Save-As: creating a hybrid urban landscape of the best aspects of the what-is now-with what could be, socio-politically and eco-culturally.

\section{RIGHT NOW}

In the following, I outline several real-world Save-As projects and then move to the pedagogy and touch-point-tactics of the 1st year architecture design studio projects that I have formulated that are in line with, and building ideologically on the Save-As Detroit projects. How these pedagogical approaches are implemented in the classroom and how they connect the students to real-world projects, is an important focus.

Most of us are familiar with real-world, successful what I call "save-as" projects, such as the High Line in New York City. The High Line was originally an elevated section of decommissioned train tracks that was turned in to an award-winning, public park and promenade. Currently in Detroit, like-minded save-as projects are also gaining positive feedback and momentum. From Lonely Planet's article August 2017: Detroit, America's Most Ambitious Renovation Project "Those investing in the city are, for the most part, respecting that heritage by choosing to restore, not replace, gambling that the extra expense of a renovation will yield returns in character." 1 


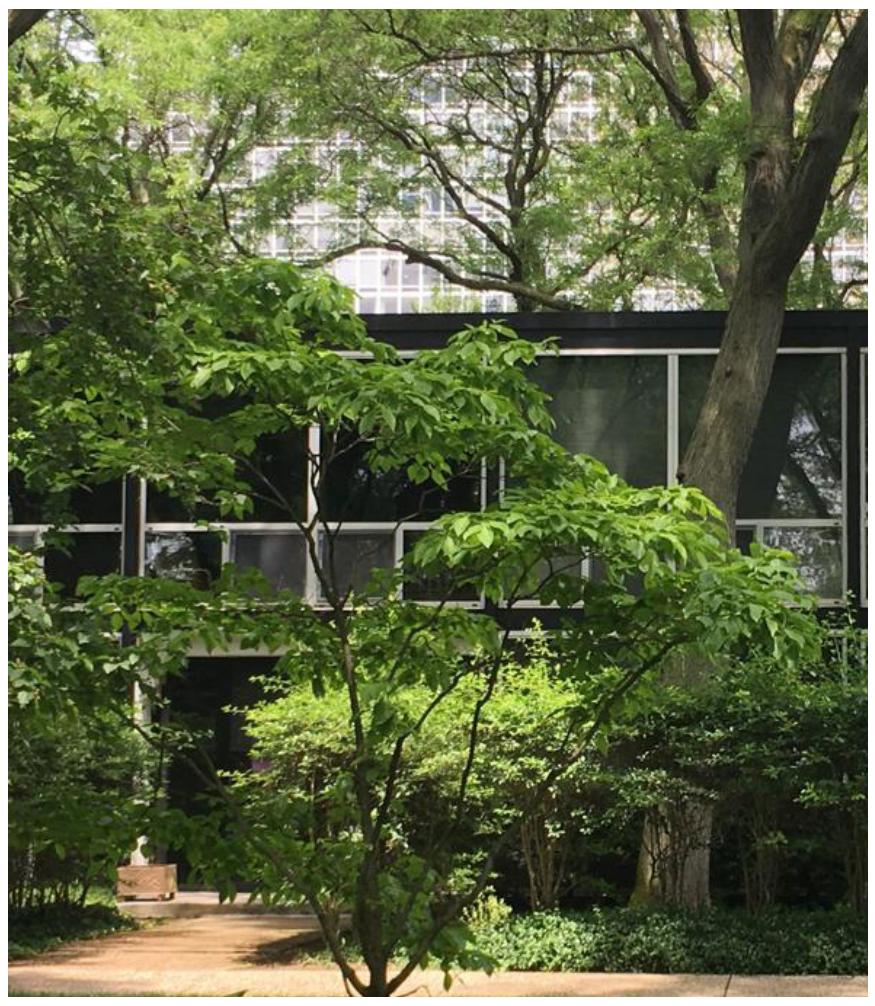

Figure 1. Lafayette Park, Detroit. Photo credit: Giovanna Galfione-Cox

While our School understands that 1st year students are not knowledgeable or skilled enough to sensitively engage with developers or community members, we have an organization housed within the SOA, The Detroit Collaborative Design Center, which is poised to do just that. Similar to what I understand the Live Project in the UK does, the DCDC is compared to a teaching hospital for architects: both professionals as well as upper-level \& graduate students work together on urban planning, design and community engagement with other nonprofits. The DCDC has created various engagement tactics designed to help organizations vocalize their wants and needs. Their tactics have benficially influenced my methods of teaching. In wanting to engage my students with local projects, I implement a series of pedagogical tactics, based on the DCDC's tactics, that are aimed at engaging students who can't be in the trenches.

\section{THE HUNCH TO MERGE ACADEMIC WITH REAL-WORLD PROJECTS}

My hunch is that Save-As urban projects create potential overlaps for academic projects, or touch points, to engage architecture students, even peripherally. As a way to engage freshmen students with successful projects and ideologies, in academic projects I merge the DCDC's tactics with the Save-As touch points and call these touch-point-tactics. Touch point tactics don't exist in a vacuum, they aren't necessarily "covered" in one class or exercise; they are woven in and overlap each other, reinforced through the semester and in their education. Examples of some touch point tactics are:

\#1: Conversations about the University's Mission.

\#2: Collaborating \& Engaging.

\#3: Making Objects \& Being-in-the-world: Having agency.

\#4: Research \& Programming: Understanding real-world strategies and contexts.

\#5. Siting: Location proximity allows for that boots-on-theground aspect that is experienced best from being where things are happening.

Merging architectural projects with real-world projects is based on a hunch: that real world projects are ideal vehicles to complement the spirit of academic projects. Real world projects that are responding to socio-political or eco-cultural challenges, through the Save-As vein, add a layer of agency to the student's education, even at the 1st year level; emphasizing the importance of societal critique, observation and engagement. While my students are relatively 'green' freshmen and therefore not directly influencing these external, real-world urban revitalization projects, the projects are connecting students to their urban community and contemporary urban philosophies. Connections between student to student, and student to both the internal School community as well as the broader, external community, reinforce our being in the world through a social, educational and urban mission.

Touch Point Tactic \#1: We hold Conversations with students about how to work within the framework of the University of Detroit Mercy's Jesuit and Mercy Mission: of social justice, education of the whole student, and urban engagement. The unique context of teaching within the only Jesuit and Mercy School of Architecture in the United States instills in these students the prioritizing of humanity-along with design.

Touch Point Tactic \#2: Collaborating within studio as well as in the School, through writing, drawing and model making, encourage students to work together to critique, research and build off of each other's ideas; ultimately preparing them for professional life. Plus, collaborating breaks down perceived barriers so they understand they are more alike than they are different. Conversations with students about the tactics and nuances in methods of collaboration, without taking over or dictating, both with their peers as well as outside community members, are important in underscoring equitable approaches. One example of collaboration was when the upper-level students designed and built a simple but impactful community project along with the DCDC: The Alley Project in Southwest Detroit, aka TAP. The Alley Project is a transformed previously-abandoned lot, now with art panels, benches and work areas for kids, street artists and the community, spaces to gather, hold workshops and create art. Students are taken to the site to witness what their peers have accomplished and the real-world impact of collaboration.

Engaging through field trips such as to TAP, tours and events in the community reinforce the student's awareness and understanding of interesting local projects as well as challenging social 


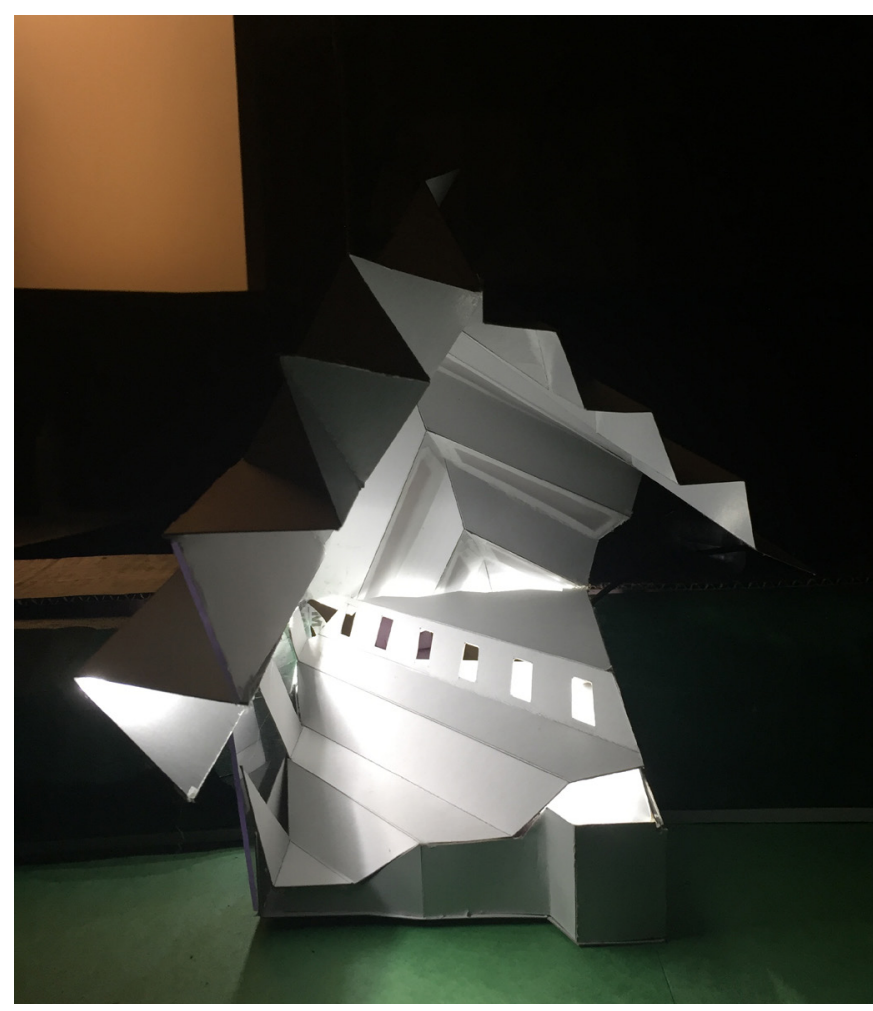

Figure 2. Paper Folding Exercise. Photo credit: Allegra Pitera

conditions. Another project that touches on some of these challenging social conditions is Detroit Mercy faculty Emily Kutil's photography exhibit called Black Bottom Street View. Similar to Google's Street View, the exhibit at the Detroit Library main branch in March 2019, documented block by block the old neighborhood before it was leveled during the 1950s and 1960s. ${ }^{2}$ City developers at that time forced the Black Bottom neighborhood citizens to move so they could build a freeway and Mies van der Roh's Lafayette Park development. "Lafayette Park was once the site of Black Bottom, named this for its rich soil, according to the Detroit Historical Society. Many Blacks who moved from the South settled in Black Bottom". Due to segregation, "they really couldn't live very many places in the city," says Marsha Music, a park resident whose father, Joe Von Battle, owned Joe's Record Shop north of Black Bottom at Mack Avenue and Hastings Street" ${ }^{3}$. Through conversation and engaging with historical issues of social justice such as the Black Bottom neighborhood, students begin to embrace their responsibility as future professionals; to be aware of the many complex social, economic and cultural layers of engagement and to become in some way that is their own, an agent of societal change.

Touch Point Tactic \#3: Making and Being-in-the-world. In the Foldable Architecture project, a continuation of the folded paper process, we shift scale to full-scale, occupiable, human-centric folded shelters designed to be portable and set up easily. Heidegger addresses the notion of the dwelling in terms of our human reality, the word 'dasein' meaning Being-in-the-World. He emphasizes the importance of connecting the architecture student to the world and the communities around them, so that they develop a sense of belonging and agency. The Foldable Architecture project, a portable single-person shelter that students design and create, provides the foil for the connection to being-in-the-world.

\section{TEACHING METHODS}

\section{Pedagogy \& Play: A Teaching Methodology}

So how do we make these relatively serious real-world issues engaging and relevant to 1st year architecture students? I craft my studios to make the foundational design principles' focus and processes engaging for the studentsby utilizing an aspect of 'play' in the projects. I hope that by engaging students, I am helping to connect them to the larger purpose of architecture: creating spaces for real humans, helping people feel like they belong: designs that impact the experience of being.

There is precedent for the role of play in architecture. In his TED talk June 3, 2019, BIG founder Bjarke Ingels' presentation addresses how BIG's design attitude often embraces the aspect of play. He discusses how the word design and form are conceptually connected: "The Danish word for design is formgivning: to give form to that which has not yet been given form. In other words, to give form to the future. As human beings, we have the power to give form to our future" ${ }^{\prime 4}$. He goes on to address a few of the Bjarke Ingels Group's building designs which incorporate aspects of play in their realized forms, such as Lego ${ }^{\circledR}$ House aka The Home of the Brick in Billund, Denmark. BIG's design attitude often embraces the aspect of play and agency in the ability to create form. Which leads us to Tactic \#3.

Touch Point Tactic \#3: Making Objects \& Being-in-theworld. We start 1st year by creating simple folded paper containers from the series of books by Paul Jackson. These containers evolve through a series of 2-D and 3-D investigations, to more architectonic forms which touch on aspects of occupiable space. Students find it fun, but they also gain confidence, feel empowered in giving form and develop skills which they can then later utilize in the larger purpose of making and creating architecture. Step 1: Making folded paper forms. Step 2: Analyzing the folded forms through drawing and creating new folded paper 'nets': 2D designs, or patterns, from which to make a new form. Step 3: Incorporating small LED lights, we explore how to capture light within a folded form. Students begin to understand the power of light in 3D form.

Then we shift scale to create the Foldable Architecture project: folded shelters specifically designed to be portable and easily set up. The scale of these shelters is to the students' own body dimensions. So the students each must exhibit their designs as they are being carried, set up and finally, occupied.

Touch Point Tactic \#4: Research \& Programming. At the 


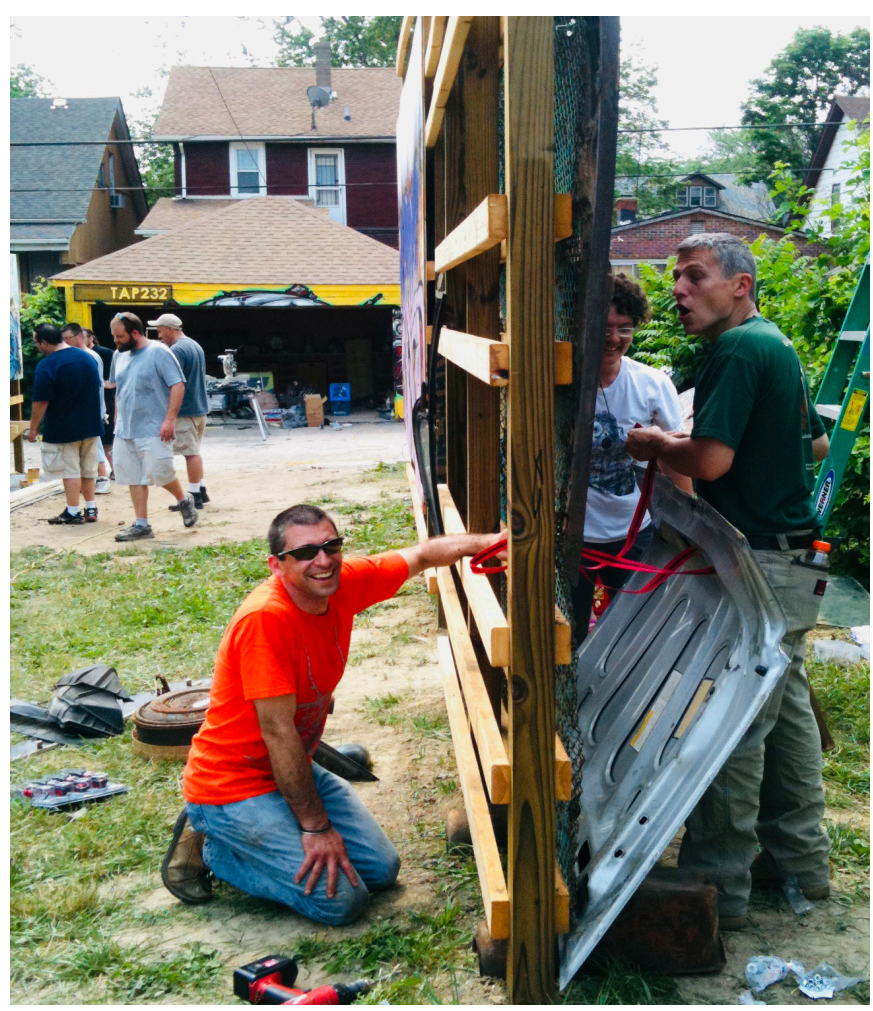

Figure 3: Touch Point Tactic \#2: The Alley Project. Photo credit: Allegra Pitera

end of the 1st semester studio, we take the class to explore 1st-hand a local Save-As example called the Dequindre Cut Greenway. The students experience first-hand through both site visits and research as part of the Site Analysis. The Cut has some similar characteristics as the High Line. 100 years ago, the Cut was conceived as a rail line, 'cut' below street level (as opposed to the elevated train tracks of the High Line). The Cut provided a relatively hidden, prime spot for graffiti artists. Now, the Greenway is a bike and pedestrian path in a park-like setting, retaining the graffiti. The Greenway celebrates the existing Detroit while embracing the future.

Touch Point Tactic \#5: Siting. The final fall semester project, Light House: Beacon for the Community, is sited within and connects philosophically with the Dequindre Cut Greenway project. The intentionality behind crafting the Dequindre Cut class project is to build on the semester-long series of process explorations rooted in the human scale and capturing light within a folded form.

During the process, students utilize digital tools to merge and visualize images of their designs with the Dequindre Cut site. Students design small scale, occupiable community spaces. These conceptual designs are intended to attract and engage visitors and local community alike. The follies create physical touch-points along the Greenway to celebrate the neighborhood, the city and citizens in and around the Dequindre Cut.

\section{ACADEMIC DESIGN PROCESSES \& THE HUMAN CONTEXT}

Not all real-world touch-point projects need to be built ones. In the 2nd semester of 1st year studio, we research the quilts from The Gee's Bend Quilters Collective from Gee's Bend, Alabama. The quilting group has evolved over generations, initially established to solve a real-world need in the community and within families: using old clothing pieces to create skillfully assembled quilts that the families could use for warmth, embracing very much a Save-As ideology: transforming and layering existing, older materials with fresh approaches and physical qualities in to something new. The quilters had limited education and opportunity so knowledge was passed from generation to generation in collaborative quilting meetings. The resulting work is beautiful. The designs of the quilt tops show a refined aesthetic; reflecting highly sophisticated minimalist tendencies which embrace the unique. Many of the compositions and textures reflect the extent to which the quilters were influenced by their spaces: what they saw around them in their homes and buildings, such as newspaper and magazine collaged walls. "In earlier years, one of the primary influences on the Gee's Bend quilt aesthetic was the newspaper- and magazine-collages used for insulation on the inside walls of homes in the rural American South" Once the quilts were discovered by those with influence and means, they were exhibited in museums all around the United States.

Basing our 2nd semester design process work on the Save-As and culturally significant work of the Gee's Bend quilters, the students embark on researching the aspect of community and fold their knowledge in to developing a series of formal 2D analysis works based on selected, individual quilts. In a playful exploration, students oscillate between 2D and 3D form, incorporating layering techniques and model making materials. Using Illustrator to draw lines of 3 different line weights over the lines of the quilt scans, students are encouraged to not just copy the shapes they perceive, but to capture and re-present their own perceived, albeit subjective hierarchy and unique shapes.

Once a hierarchy is established with the 3 different line weight shapes, lines are discarded and shades of grey are applied within the shapes. Color is captured in the final 2D version, directly from the original quilt. Working iteratively, students create a body of work including laser-cut bas reliefs and mixed media models, illustrating design principles such as hierarchy, balance, proximity, repetition and space.

When we consider that a quilt is essentially a physical assemblage of varying fabrics, colors, shapes and sizes, that are juxtaposed to create an organizational structure and hierarchy, we can begin to conceptually connect design principles with the quilts: creating touch-points of conceptual overlap. Formally, the quilt designs have the potential to imply layers in themselves: of circulation, landscape, building and gathering spaces. With a shift of scale and sited within an existing urban context, the designs imply real-world potential of mapping, circulation, landscape \& built space.

One tactic taken from the Gee's Bend quilters is collaboration. I create a game where students swap models with each other to see who can best 'improve' their team mate's model. A good-natured 


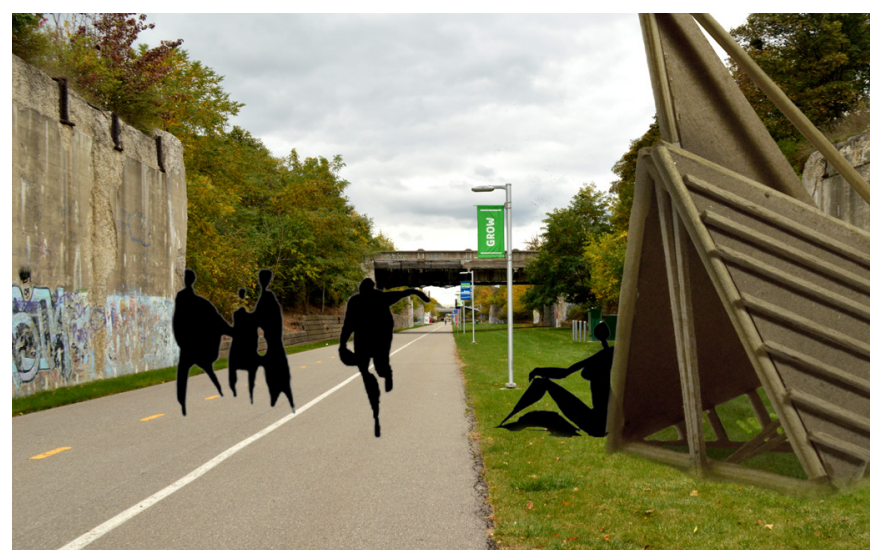

Figure 4: Touch Point Tactic \#5: Siting. Student Work, Fall semester, Dequindre Cut. Image credit: Joe Loria

competition, it reinforces the role of collaboration in making architecture.

We base our final project on the Fitzgerald Neighborhood Revitalization plan which is aimed to transform city-owned abandoned property that currently detract from the neighborhood. The University of Detroit Mercy is the red outlined rectangle, The School of Architecture is the pink circle, showing our proximity to the site. The students have access to much of the DCDCs engagement activities, one to guide Fitzgerald community members to develop a strategy.

The Fitzgerald residential neighborhood is one of the many Detroit neighborhoods that has struggled with poverty and abandoned properties over the past few decades. Support from multiple foundations, the initiative led by the City of Detroit allowed the community the resources to develop a revitalization master plan. Rather than addressing individual abandoned lots, the strategy they took is more holistic. The master plan consists of gardens, paths and a series of connecting public parks that weave through the neighborhood connecting homes with vibrant public spaces. "The Fitzgerald Revitalization Project is an to stabilize and strengthen a neighborhood by transforming publicly owned vacant

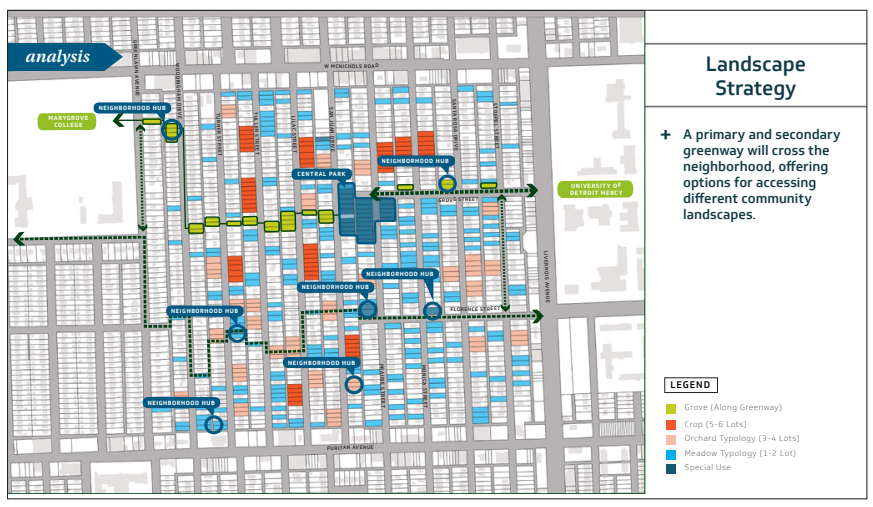

Figure 3: The Livernois Revitalization Plan Project, July 6, 2016. Image Credit: Spackman Mossop Michaels land and buildings into community assets". ${ }^{6}$ As the Fitzgerald neighborhood is located across the street from the University of Detroit Mercy and the School of Architecture, we can see the neighborhood from our studio windows, and walk to it easily. It is an exciting real-world project that students have the opportunity to see and experience first-hand.

The developers and citizens of the Revitalization project could easily have taken the 'Save' route; it would have been cheaper and faster to raze abandoned buildings and pave over vacant lots. But along with getting rid of the unwanted structures, part of the result would be destroying the existing strong, vibrant community foundation. The master plan shows an understanding of the power of the bigger vision: building up from the existing homes and spaces to create a neighborhood of and for the Detroiters who have lived there for generations: the real stakeholders. As Mayor Mike Duggan said: "We are doing neighborhood revitalization to keep neighbors here who have stayed here through the tough times." 7 Building up from existing spaces and creating public spaces for its citizens provides The Fitzgerald Revitalization project with potent Save-As impact.

We chose this park on the edge of the neighborhood for our final project site, the SOA is where the pink circle is. Currently, the park is an informal weekend market with tables, benches and murals. The students embark on Site Research and Analysis, focusing on Strengths, Weaknesses, Opportunities and Threats. We decide that an opportunity for programming would be for the students to design a community center and public park integrated with the paths at the edge of the Revitalization plan. Called The Fitzgerald Community Center, the pedagogy piggy-backs on the Revitalization strategy. The intention is to engage the students in their neighborhood context through programming: Seeing a need for a community center and focusing on solving that need as a complement to the Revitalization plan. As part of the making and design process work, earlier quilt diagrams are abstracted \& constructed as sites, as a way to organize landscape and enclosed spaces. A challenge for the students is to connect their paths with the neighborhood, understanding the cultural and socio-economic struggles of the Fitzgerald neighborhood, which are not unlike the Gee's Bend community.

\section{TEACHING DESIGN 'LANGUAGE'}

Massimo Vignelli once said: "Good design is a language, not a style." Through building on existing Save-As real world projects, I intentionally create a fundamental academic framework: underscoring the significance of a multi-faceted but systematic language within the design process; as a visual as well as an intuitive and subjective communication system.

Experience has taught me that students become nimble at problem solving when they are challenged with approaching design problems from various tangents rather than from one direction. As such, I integrate various creative, visual, and conceptual 'languages' in teaching methodologies to best guide students in learning how to think. My pedagogy is rooted in connecting ideas from 


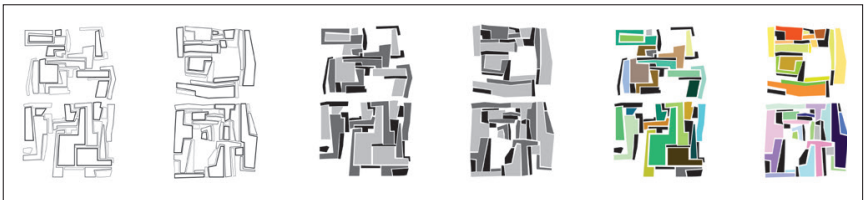

Figure 5: Student Quilt Process Work. Image Credit: Chelsea Short

project to project that address learning outcomes from divergent vectors. I refer to this as 'weaving a thread' of ideas, strategies, and approaches. Retaining a thread of ideas through the semester, the projects and the students themselves, evolve. Beyond form-generating exercises, I am fascinated with developing academic process

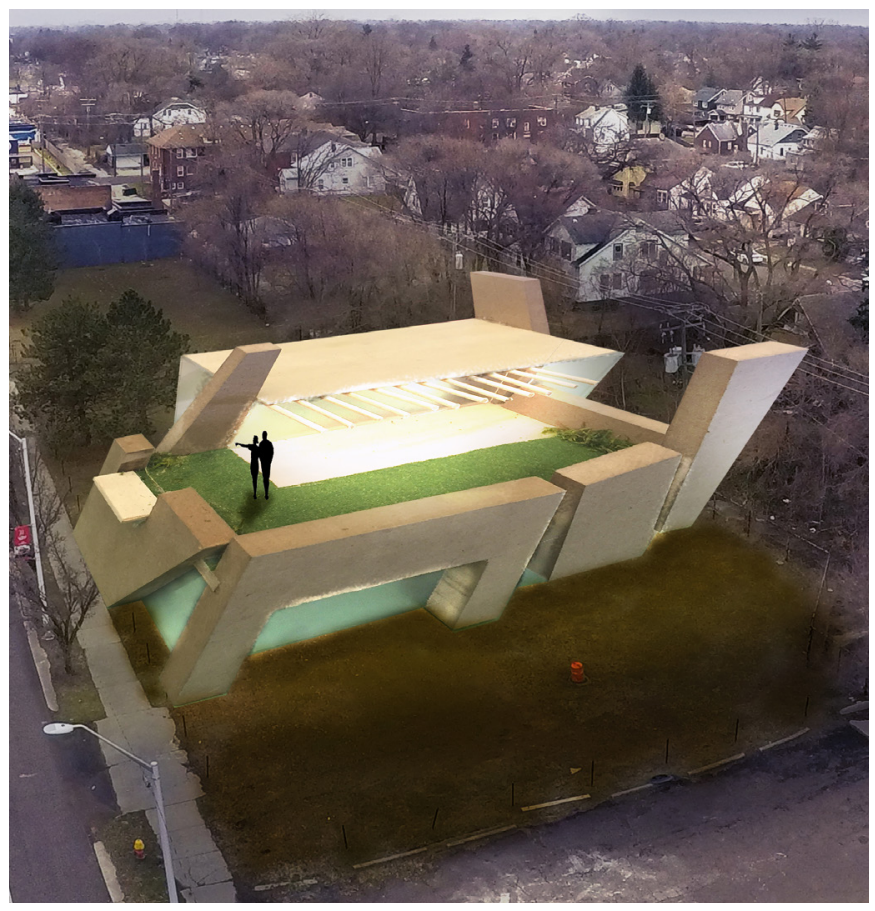

Figure 6: Final Project on the Fitzgerald Revitalization Site park. Student Work. Image Credit: Angela Lazarte

projects that create intuitive connections to real-world projects: I am working on the hunch that incorporating a 'design language' implementing a set of visual elements, assembled under the structural 'grammar' of design principles, will create touch points of the student's intuitive strategies to successful, real-world projects; solidifying their understanding of their being in the world through the physical, urban Save-As context. As Juhani Pallasmaa states in his book The Eyes of the Skin: Architecture and the Senses." In artistic works, existential understanding arises from our very encounter with the world and our being-in-the-world-it is not conceptualized or intellectual".8

The Save-As methodology as seen through our University's Mission lens, underscores humanity as well as design and urban strategies. Through touch-point-tactics the humanitarian focus can resonate for architecture students. Therefore, Save-As is a foundation to build up and better; Save-As to benefit students, cities, and communities.

\section{Notes}

1 Michael Hodges, "Detroit's Black Bottom Resurrected at Detroit Public Library," The Detroit News, January 9, 2019 , accessed June 1, 2019, https://www.detroitnews.com/story/ entertainment/2019/01/09/detroit-black-bottom-detroitpublic-library-main-branch-emily-kutil-marsha-music-hastings-street/2482276002/

2 Ping, T. (2017, August). “Detroit: America's most ambitious renovation project," Lonely Planet, accessed May 13, 2019, https://www.lonelyplanet.com/usa/great-lakes/detroit/travel-tips-and-articles/detroit-americas-most-ambitious-renovation-project/40625c8c-8a11-5710-a052-1479d27680c5

3 Meghan Kruger, "Black Bottom: Life before Lafayette Park," Blac Detroit, November 4, 2013, accessed May 8, 2019, https://www.blacdetroit.com/news-features/black-bottomlife-before-lafayette-park

4 Niall Patrick Walsh, "Bjarke Ingels TED Talk: Floating Cities, the Lego House and Other Architectural Forms of the Future," ArchDaily, June 4, 2019, accessed June 18, 2019, https:// www.archdaily.com/918438/bjarke-ingels-ted-talk-on-floating-cities-and-the-lego-house

5 The Quilts of Gee's Bend, "Collective History," (c)2004-2005, accessed June 11, 2019, http://www.quiltsofgeesbend.com/ facts.html

6 "Fitzgerald Revitalization Project," July 6, 2016, accessed April 20, 2019, http://www.fitzgerald-detroit.com/

7 Pinho, K. "Fitzgerald neighborhood's \$4 million-plus project to be led by The Platform, Century Partners," Crain's Detroit Business. accessed June 11, 2019,: https://www.crainsdetroit. com/article/20170405/news/170409919/fitzgerald-neighborhoods-4-million-plus-project-to-be-led-by-the

8 Pallasmaa, Juhani, The Eyes of the Skin: Architecture and the Senses (West Sussex, John Wiley \& Sons Ltd, 2012), 28. 